\title{
Aesthetic Aspects of Technology-Mediated Self-awareness Experiences
}

\author{
Junji Watanabe \\ NTT Communication Science Laboratories, \\ Nippon Telegraph and Telephone Corporation, Atsugi, Japan \\ watanabe.junji@lab.ntt.co.jp
}

\begin{abstract}
Today's media technologies can provide experiences where people become aware of their fundamental attributes and unconscious behaviors. In this paper, I introduce three interface technologies designed to mediate such self-awareness experiences, and interpret them from an aesthetical viewpoint.
\end{abstract}

Keywords: Self-awareness experiences, Interface technologies, Aesthetics, Saccade-based display, Galvanic vestibular stimulation, Heartbeat picnic.

\section{Introduction}

Technologies have been tremendously important for expanding our sphere of existence and solving problems. In the years ahead, I envision that technologies will play an important role in probing the depths and opening up new vistas of the human mind. Interface technologies available in today's modern society can provide experiences where people become aware of fundamental attributes and unconscious behaviors to which they normally pay little attention as they lead their lives. My colleagues and I have developed unique interface technologies based on the perceptual characteristics of humans and have had opportunities to introduce them to a wide range of people in the technology demos (e.g., [1-4]), presentations at science museums (e.g., [5-6]), and art festivals (e.g., [7-9]). Through these exhibitions, I realized that experiences mediated by the interface technologies can promote people recognize self and aware of new rules as to how they relate to their environments.

The self-awareness experience and the aesthetic judgment defined by Immanuel Kant are analogous in that both are based on subjective appreciation of a phenomenon and implication of its universality. This is because the aesthetic judgment is related to the senses of being "purposive without a specific purpose" (a foundation of accepting existence of a specific phenomenon) and "lawful without a specific law" (a foundation of supporting its universality) [10]. Here I conjecture that the selfawareness experiences by the technologies can be a way of understanding ourselves by extending subjective experience to others (aesthetic approach), without assuming objective observation (scientific approach). In this paper, I introduce three specific themes of the self-awareness experiences motivated by the aesthetic approach: themes about constraints of perception (section 2), behavior (section 3), and body (section 4). 


\section{See What You Throw off from Visual Perception}

It is well known that humans actively collect information from the outside world, but this inevitably means that they also discard information. Consider vision, for example. It is known that when one looks in the direction one wants to see, the eye is moved very rapidly, but one will not perceive any movement of visual images. The visual information during rapid eye movements is discarded in order to build up a fixed stable visual scene. This capability of the brain to construct and maintain "a stable world image" is critical for our everyday lives.

Using an interface technology, we can get a real sense of how we construct stable world images. In the interface technology, I and my colleague (H. Ando) and supervisors (T. Maeda and S. Tachi) focused on the information that is discarded and leveraged this information to develop a novel visual information presentation method $[2,11,12]$. To describe the principle of the technology, let us first consider the scheme illustrated in Fig. 1(a) consisting of a one-dimensional array of lights that moves rapidly back and forth to produce a two-dimensional (2D) visual image. This type of visual display is already available on the market (e.g., [13]). An alternative scheme is illustrated in Fig. 1(b). In this scheme, which we call "Saccade-based Displays," the array of lights does not move but an observer's eye movement called a saccade is made in front of rapidly flashing lights. The one-dimensional flashing pattern during the eye movement is projected onto different locations of the retina, and these projections create a coherent 2D image momentarily. Visual displays based on this perceptual phenomenon can present full life-size color visual images without a projection screen (even in midair) using only a single column of light (Figs. 2), and have been used in the field of arts and entertainments [6, 14, 15].

Generally, the selective culling process of visual images does not raise to the level of consciousness, but in our information presentation scheme, the act of seeing itself is experienced as one's own personal visual image. This experience makes people aware of their own eye movements, which they had never been conscious of before. This calls attention to how we perceive the world and how much information we discard.
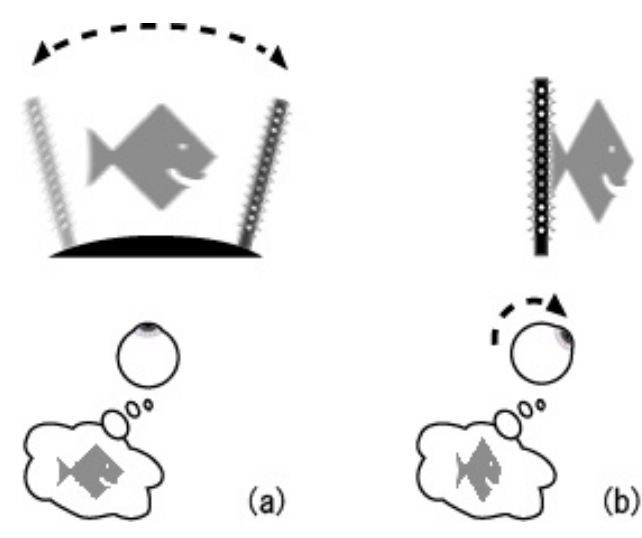

(a)

Fig. 1. Schematic drawing of the information presentation principle using a moving light column (a) and that using the observer's eye movements (b) 


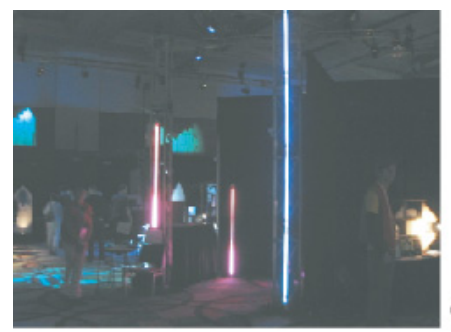

(a)
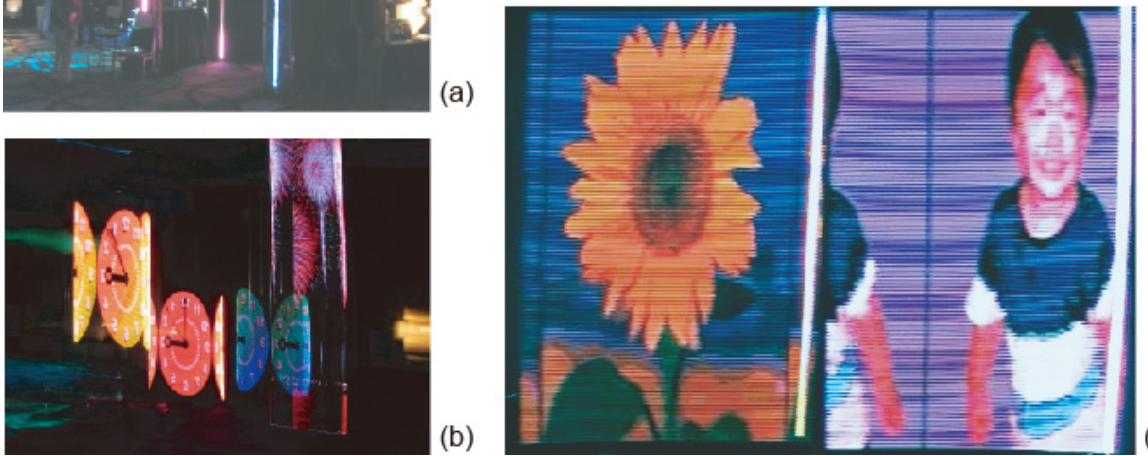

(c)

Fig. 2. Perceived image with observer's eyes static (a). Two LED columns $1.8 \mathrm{~m}$ in height and one LED column $4 \mathrm{~m}$ in height are shown in this photo. An example of perceived images displayed with Saccade-based Display (b). Life-size photographic images can be presented (c). The images are 128 pixels in vertical and horizontal resolutions with 4-bit color depth. Images (b) and (c) were taken with a slow-shutter rotating camera.

\section{Save Yourself from Constraints of Free Will}

With recent advances in personal electronic devices, ubiquitous sensors, and highspeed networks, technologies have become transparent, and they affect, and occasionally control, us without our noticing. Under these circumstances, both attributing everything to one's free will and to being forced by the outside world are problematic. From this perspective, I and my colleagues (H. Ando and T. Yoshida) have devised a scheme, called "Save YourSelf !!!" (Fig. 3), which can create a physical experience that enables one to sense "free will" under unseen control [7].

The basic principle of the scheme is to distort one's sense of balance using a galvanic vestibular stimulation (GVS) interface [16]. The GVS interface (a headset in Fig. 3) can stimulate the nerves associated with the three canals in the inner ear with a weak current. The GVS causes a lateral virtual acceleration toward the anode and makes users feel like their body is lurching or swaying even though they may not be actually moving at all. In addition, as they walk it can induce lateral divergence from the intended straight line. If GVS control is put into the hands of another person, the user can be made to walk in a certain direction. This scenario reflects a situation where a person's behavior is dictated by others. However, "Save YourSelf !!!" is based on the scheme of observing one's own state from an external perspective. In this scheme, a participant puts on the GVS interface and walks freely while holding a clear plastic bowl containing water with both hands. A monitor-like figurine floats on 


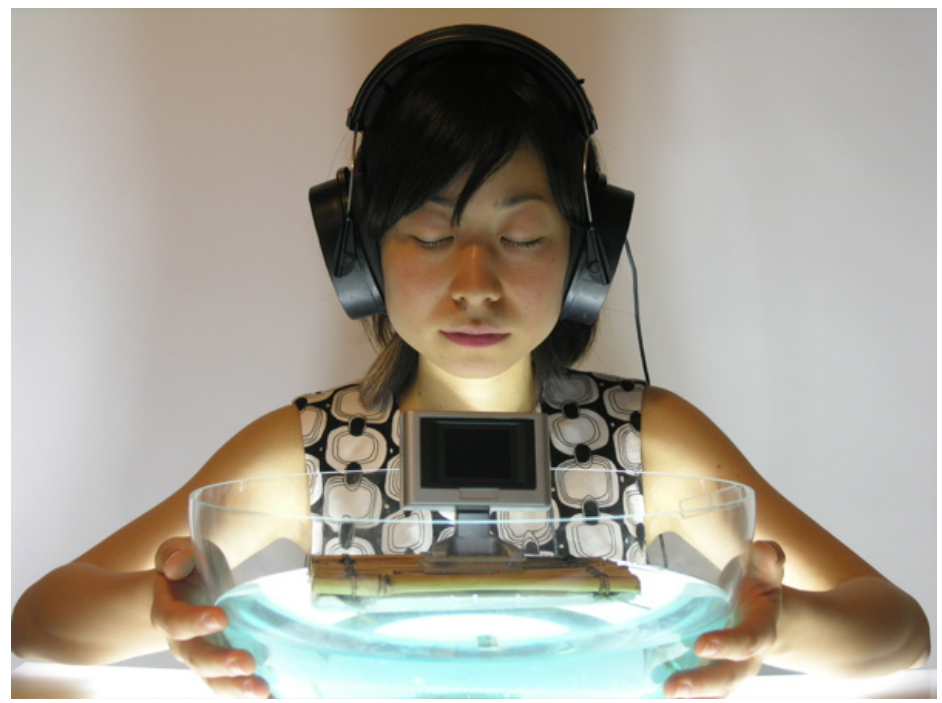

Fig. 3. Photograph of "Save YourSelf !!!” ( Tomofumi Yoshida)

the water in the bowl. The movement of the figurine is linked to the participant's sense of balance since the data obtained by a direction sensor embedded in the figurine is sent to the GVS interface. The participant walks while keeping the balance of the figurine floating on the water. In this experience the relation between the self and the outside world is externalized, and observing the figurine floating on the water (a metaphor of the externalized self) has participants realize the nature of self-identity in today's life.

\section{$4 \quad$ Real Sense of Life Generated by Touching Heartbeat}

Although we do become conscious of the body under certain circumstances, (e.g., when we catch a cold), we are oblivious to the body of self. For example, although we know that the heart is indispensable for every human being, we lead our lives without paying much attention to it. Here, for a workshop called "Heartbeat Picnic," I and my colleagues (Y. Kawaguchi, K. Sakakura and H. Ando) developed a simple device as shown in Fig. 4(a) for reaffirming people's lives [8]. The participants were asked to hold a stethoscope in one hand and a vibration speaker (referred to as the heart box) in the other as shown in Fig. 4(b). When the stethoscope was placed on their chest, their own heartbeat was output as both sounds and vibrations from the heart box, which enabled them to not only hear their own heartbeats but also feel them as vibrations. Since the workshop was held outdoors, they were free to move about as if they were having a picnic, and they were able to feel the changes in their heartbeat with their own hands. Moreover, as shown in Fig. 4(c), by exchanging their heart boxes with those of other participants, they were able to feel the differences between their own heartbeats and those of others. The experience of touching heartbeats, which is 
usually impossible, provided the participants with the opportunity to appreciate the importance of his/her own life as well as the lives of others.

Life appreciation workshops are usually held in a natural environment where participants can directly experience the abundant life. In every day life, however, there are almost no opportunities for us to appreciate our own lives. This workshop is aimed at enabling participants to experience the reality of life by evoking the imagination through the sense of touch rather than having to escape from their modern everyday environment. I believe that the sense of touch enables us to have a physical and realistic connection with the wealth of our lives.
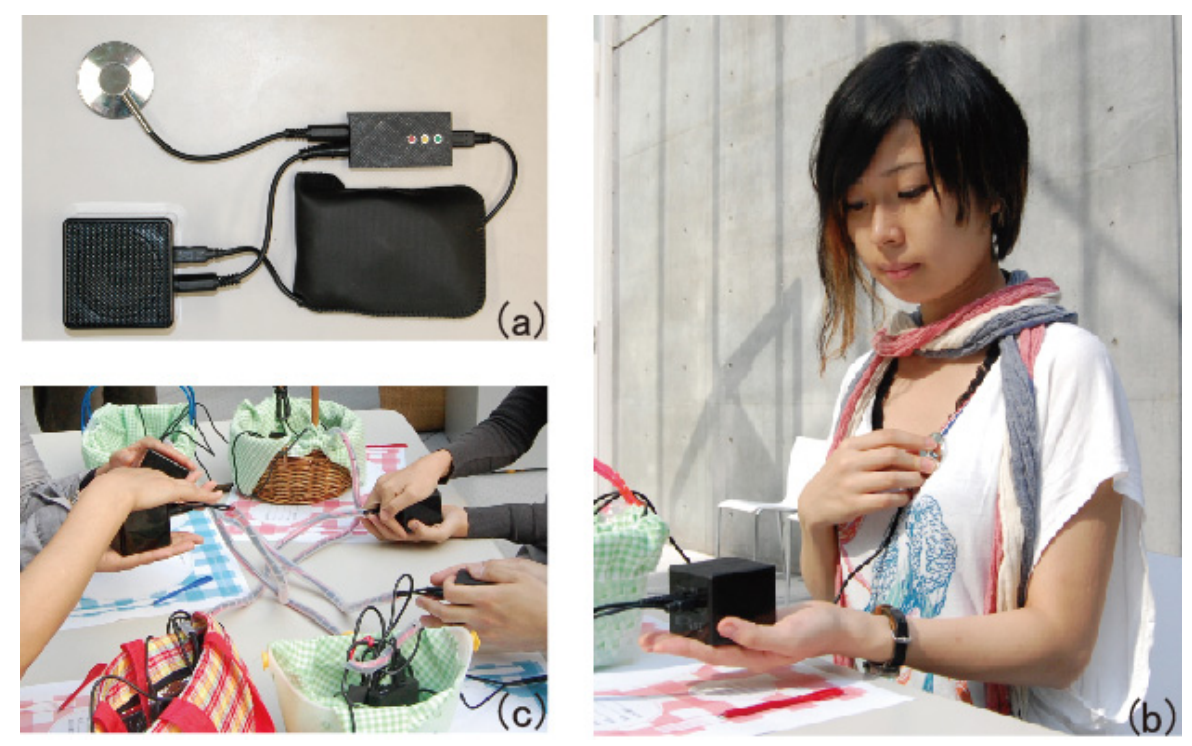

Fig. 4. Photographs of "Heartbeat Picnic." Equipments used in the workshop are stethoscope, vibration speaker (heart box), signal processing circuit, and batteries (a). Equipment in use (b). Exchange of heart boxes among participants (c)

\section{Conclusion}

One doesn't know the "self" initially, but only gradually becomes acquainted with it as it is manifested though interaction with the environment and others. The interface technologies described above can provide unique experiences of self with implications of the common features of human beings. I hope that feeling unconscious characteristics of ourselves broadens perspectives of ourselves and frees ourselves from the constraints. Although the notion of applying deep insight into the aspects of "the self" may strike one as the realm of philosophical or art practices, it has important implications for everyday living and an affinity for interpretation from the viewpoint of aesthetics. 
Open Access. This chapter is distributed under the terms of the Creative Commons Attribution Noncommercial License, which permits any noncommercial use, distribution, and reproduction in any medium, provided the original author(s) and source are credited.

\section{References}

1. Ando, H., Amemiya, T., Maeda, T., Nakatani, M., Watanabe, J.: Embossed Touch Display: Illusory Elongation and Shrinking of Tactile Objects. In: Emerging Technologies, SIGGRAPH 2006, Boston, U.S.A. (2006)

2. Ando, H., Watanabe, J., Amemiya, T., Maeda, T.: Full-scale Saccade-based Display: Public/Private Image Presentation based on Gaze-Contingent Visual Illusion. In: Emerging Technologies, SIGGRAPH 2007, San Diego, U.S.A. (2007)

3. Ooshima, S., Fukuzawa, Y., Hashimoto, Y., Ando, H., Watanabe, J., Kajimoto, H.: /ed Gut Feelings when Being Cut and Pierced -. In: New Tech Demo, SIGGRAPH 2008, Los Angels, U.S.A. (2008)

4. Watanabe, J., Kusachi, E., NOSIGNER, Ando, H.: Touch the Invisibles. In: Information Aesthetics Showcase, SIGGRAPH 2009, New Orleans, U.S.A. (2009)

5. Ando, H., Watanabe, J.: Sensory Circuit Collection. In: Device Art Collection. National Museum of Emerging Science and Innovation (MIRAIKAN) (2009)

6. Ando, H., Watanabe, J., Tabata, T., Verdaasdonk, M.A.: Saccade-based Display -blink to see __. In: Device Art Collection. National Museum of Emerging Science and Innovation (MIRAIKAN) (2011), http: / / www . junji .org/saccade/

7. Ando, H., Yoshida, T., Watanabe J.: Save YourSelf !!! Ars Electonica Center, Linz Austria (2007), http: / /www. junji.org/saveyourself/

8. Watanabe, J., Kawaguchi, Y., Sakakura, K., Ando H.: Heartbeat Picnic. Ars Electronica Exhibition, OKcenter, Linz, Austria (2011),

http: / / www . junji.org/heartbeatpicnic/

9. Watanabe, J., Kusachi, E., Ando, H.: Touch the Invisibles. In: 12th Japan Media Arts Festival, Roppongi, Tokyo, Japan (2009)

10. Kant, I.: The Critique of the Power of Judgment (1790)

11. Watanabe, J., Ando, H., Maeda, T., Tachi, S.: Gaze-contingent Visual Presentation based on Remote Saccade Detection. Presence: Teleoperators and Virtual Environments 16(2), 224-234 (2007)

12. Watanabe, J., Maeda, T., Ando, H.: Gaze-contingent Information Display with Electrooculo-graph-based Saccade Detection. ACM Trans. Applied Percept 9(2), 1-12 (2012)

13. Dynascan Techinology Inc. (2006), http: / /www. dynascanusa.com/

14. Bell, B., Parks, T.E., Post, R.B.: Elusive Imagery of the LightStick. Leonardo 19(1), 3-10 (1986), See also the artwork by Bill Bell at his website "Subliminary Artworks" http: / / www. subliminaryartworks. com

15. Watanabe, J., Tavata, T., Verdaasdonk, M.A., Ando, H., Maeda, T., Tachi, S.: Illusory Interactive Performance by Self Eye Movement. Sketches. In: SIGGRAPH 2004, Los Angeles, U.S.A. (2004)

16. Maeda, T., Ando, H., Amemiya, T., Nagaya, N., Sugimoto, M., Inami, M.: Shaking the World: Galvanic Vestibular Stimulation as a Novel Sensation Interface. Emerging Technologies. In: SIGGRAPH 2005, Los Angels, U.S.A. (2005) 